\title{
No Correlation of the Disease Severity of Influenza A Virus Infection with the rs12252 Polymorphism of the Interferon-Induced Transmembrane Protein 3 Gene
}

\author{
Yong-Chan Kim ${ }^{a, b}$ Byung-Hoon Jeong ${ }^{a, b}$ \\ ${ }^{a}$ Korea Zoonosis Research Institute, Chonbuk National University, Iksan, and bepartment of Bioactive Material \\ Sciences, Chonbuk National University, Jeonju, Republic of Korea
}

\section{Keywords}

IFITM3 - Interferon-induced transmembrane protein 3 . 2009 influenza A pandemic . Genetic polymorphism .

H1N1 - Epidemiology

\begin{abstract}
The 2009 H1N1 influenza pandemic, which involved a more pathogenic virus than seasonal influenza viruses, rapidly spread around the world and caused many deaths in humans. The members of the interferon-induced transmembrane (IFITM) protein family prevent viral replication and are crucial for defending the host cell against influenza $A$ virus (IAV). Several studies suggest that the CC genotype at the single nucleotide polymorphism (SNP) rs12252 of IFITM3 confers a genetic predisposition to pandemic influenza $A$ in Europeans and Han Chinese, although one study in a British cohort failed to show an association. In order to examine whether an SNP of the IFITM3 gene is correlated with the disease severity of pandemic IAV (H1N1) infection in a Korean population, we investigated the genotype and allele frequencies of this polymorphism in 300 healthy Koreans by automatic direct sequencing and compared the disease severity based on epidemiological studies of the $\mathrm{H} 1 \mathrm{~N} 1$ virus reported in several countries. The frequencies of the CC gen-
\end{abstract}

\section{KARGER}

(C) 2017 S. Karger AG, Basel

E-Mail karger@karger.com

www.karger.com/int otype and the $\mathrm{C}$ allele in the IFITM3 polymorphism were higher in the Korean population than in the European populations, but not in Chinese and Japanese populations. The prevalence of severe cases of the pandemic 2009 IAV infection in Koreans was similar to that in Europeans ( $p=0.106$ ). In addition, the prevalence of deaths among all positive cases with pandemic 2009 IAV infection in Koreans was significantly lower than that in Europeans. These results suggest that the IFITM3 genotype may not be a determinant of disease severity of IAV infection.

(c) 2017 S. Karger AG, Basel

\section{Introduction}

Pandemic 2009 influenza A infections were responsible for severe respiratory diseases, leading to more severe infections and complications than seasonal influenza [1, 2]. Viral infection mechanisms include several complicated steps. Among these, membrane fusion is an important step for enveloped viruses to enter the host cell and initiate infection. Against viral infection, host cells produce interferon (IFN)-induced transmembrane (IFITM) proteins, resulting in the stimulation of type I and II IFN [3]. IFITM proteins control viral membrane hemifusion

Byung-Hoon Jeong, $\mathrm{PhD}$

Korea Zoonosis Research Institute

Chonbuk National University

820-120, Hana-ro, Iksan, Jeonbuk 570-390 (Republic of Korea)

E-Mail bhjeong@jbnu.ac.kr 
[4]. These proteins are intrinsic antiviral defense substances that restrict a wide range of highly pathogenic viruses, including influenza A viruses (IAVs), Ebola virus, Marburg virus, severe acute respiratory syndrome coronavirus, dengue virus, and West Nile virus $[5,6]$.

The IFITM proteins are a family that typically consists of IFITM 1, 2, and 3. Among these, IFITM3 is well known for preventing the cytosolic entry of viruses in host cells $[6,7]$. In recent studies, the single nucleotide polymorphism (SNP) rs12252-C allele of IFITM3 has been shown to shorten IFITM3, leading to decreased inhibition of virus replication in vitro [8]. In addition, IFITM3 is associated with the severity of acute influenza in mice and controls influenza virus mortality [8]. Several studies suggest that the CC genotype at the rs12252 SNP contributes to severe clinical outcomes in patients with H1N1 IAV infection. Previous SNP studies in Europeans and Han Chinese indicated a relationship between this polymorphism and susceptibility to IAV infection [8, 9]. However, Mills et al. [10] could not find an association between this SNP and the susceptibility to severe IAV infection in a British cohort.

The purpose of this study was to investigate the genotype and allele frequencies of the rs12252 polymorphism of IFITM3 in 300 normal Koreans and to determine the association between this SNP and the disease severity in pandemic 2009 IAV infection through comparative analysis with previous epidemiological studies carried out in several populations, including Koreans.

Genomic DNA from healthy Korean subjects was obtained from the National Biobank of Korea at the Centers for Disease Control and Prevention. Exclusion criteria were diabetes, high blood pressure, gastritis, gastric ulcer, myocardial infarction, thyroid disease, congestive heart failure, coronary artery disease, hypothyroidism, asthma, chronic lung disease, peripheral vascular disease, kidney disease, hepatitis, tuberculosis, cerebrovascular disease, head trauma, urinary tract infection, arthritis, and cancer. The study was approved by the Ethical Committee of the Chonbuk National University and in accordance with the 1964 Helsinki Declaration and its later amendments or comparable ethical standards. Polymerase chain reaction (PCR) was performed with sense (5'-CCGCCGCTGGTCTTCGCTGGA-3') and antisense ( $5^{\prime}$-CAGGGGTTCATGAAGAGGGT- $3^{\prime}$ ) primers. These primers were designed to amplify the 236-bp IFITM3 gene product. The PCR mixture consisted of 25 pmol of each primer, $1 \times$ Taq buffer, $200 \mu \mathrm{M}$ of each dNTP mixture, and $2.5 \mathrm{U}$ of Taq DNA polymerase (Promega, USA). The amplification was carried out using an initial denaturation step at $95^{\circ} \mathrm{C}$ for $3 \mathrm{~min}$, followed by 40 cycles of denaturation at $95^{\circ} \mathrm{C}$ for $30 \mathrm{~s}$, annealing at $63^{\circ} \mathrm{C}$ for $45 \mathrm{~s}$ and at $72^{\circ} \mathrm{C}$ for $1 \mathrm{~min}$. Finally, an extension at $72^{\circ} \mathrm{C}$ for 10 min followed using an S-1000 Thermal Cycler (Bio-Rad Laboratories, USA). All PCR products were resolved on $1.2 \%$ agarose gel containing ethidium bromide. PCR products of $236 \mathrm{bp}$ were prepared using a QIAquick ${ }^{\circledR}$ gel extraction kit (QIAGEN). Automatic DNA sequencing of the PCR products purified from 300 normal Koreans was directly performed at Macrogen Inc. (Seoul, Republic of Korea) using an ABI 3730 capillary sequencer (Applied Biosystems, USA).

Eligible studies were identified by searching webbased databases. The applied search terms were "pandemic 2009 influenza A," "H1N1," "severe," "death," and "surveillance." Relevant studies were evaluated according to the following criteria: (1) surveillance was performed in European and East Asian populations; (2) the cases were classified as nonsevere cases and severe cases (intensive care unit [ICU] admission and death); and (3) the language was restricted to English.

Statistical analyses were performed using SAS version 9.3 (SAS Institute Inc., USA). The differences in genotype and allele frequencies of the IFITM3 gene and the rate of severe cases and deaths with pandemic 2009 IAV infection were compared using $\chi^{2}$ or Fisher exact tests. Odds ratios with $95 \%$ confidence intervals and $p$ values were calculated using the codominant model within the SAS 9.3 software. The Hardy-Weinberg equilibrium (HWE) was calculated using a simple HWE calculator (http:// www.tufts.edu/ mcoourt01/lab_protocols.htm). The statistical power was calculated using a statistical power calculator (http://www.dssresearch.com/toolkit/spcalc/ power_p2.asp).

To investigate genotype frequencies of the rs12252 SNP of IFITM3 in Koreans, we examined DNA samples from 300 normal Koreans through direct DNA sequencing. The mean age of healthy Koreans was 58.31 years, and $50 \%$ were male. Among the 300 normal controls, 62 (30.7\%) were homozygous for C; 55 (18.3\%) were homozygous for T; and 153 (51.0\%) were heterozygous at IFITM3.

To determine how the distribution of this SNP in normal Koreans differs from other populations, we compared our results with data reported in various countries. Interestingly, the genotype and allele frequencies of IFITM3 SNP were significantly different between Koreans and northern Europeans (Table 1). In addition, the genotype frequency of CC homozygotes was markedly higher in normal Koreans than in Europeans (odds ratio
70

Intervirology 2017;60:69-74

DOI: $10.1159 / 000479087$
Kim/Jeong 
Table 1. Genotype distribution of IFITM3 polymorphisms in several populations

\begin{tabular}{|c|c|c|c|c|c|c|c|c|c|}
\hline \multirow[t]{2}{*}{ Populations } & \multirow{2}{*}{$\begin{array}{l}\text { Total, } \\
n\end{array}$} & \multicolumn{3}{|c|}{ Genotype frequency, $n(\%)$} & \multirow{2}{*}{$\begin{array}{l}p \\
\text { value }^{\text {a }}\end{array}$} & \multicolumn{2}{|c|}{ Allele frequency, $n(\%)$} & \multirow{2}{*}{$\begin{array}{l}p \\
\text { value }^{\mathrm{b}}\end{array}$} & \multirow[t]{2}{*}{ Ref. } \\
\hline & & $\mathrm{T} / \mathrm{T}$ & $\mathrm{T} / \mathrm{C}$ & $\mathrm{C} / \mathrm{C}$ & & $\mathrm{T}$ & $\mathrm{C}$ & & \\
\hline CEU/FIN/GBR/IBI/TSI (Europe) & 360 & $335(93.0)$ & $24(6.7)$ & $1(0.3)$ & $<0.001$ & $694(96.4)$ & $26(3.6)$ & $<0.001$ & 8 \\
\hline UK & 89 & $87(97.8)$ & $2(2.2)$ & $0(0)$ & $<0.001$ & $176(98.9)$ & $2(1.1)$ & $<0.001$ & 9 \\
\hline Northern Europe & 87 & $80(91.9)$ & $7(8.1)$ & $0(0)$ & $<0.001$ & $167(96.0)$ & $7(4.0)$ & $<0.001$ & 9 \\
\hline YRI (Africa) & 59 & $49(83.0)$ & $9(15.3)$ & $1(1.7)$ & $<0.001$ & $107(90.7)$ & $11(9.3)$ & $<0.001$ & 8 \\
\hline Japan & 89 & $15(16.9)$ & $35(39.3)$ & $39(43.8)$ & 0.051 & $65(36.5)$ & $113(63.5)$ & 0.073 & 9 \\
\hline China & 197 & 49 (24.9) & 98 (49.7) & $50(25.4)$ & 0.145 & $196(49.7)$ & $198(50.3)$ & 0.061 & 9 \\
\hline Korea & 300 & $55(18.3)$ & $153(51.0)$ & $92(30.7)$ & - & $263(43.8)$ & $337(56.2)$ & - & $\begin{array}{l}\text { This } \\
\text { study }\end{array}$ \\
\hline
\end{tabular}

${ }^{a} \chi^{2}$ test comparing genotype frequencies between Koreans and other populations.

${ }^{\mathrm{b}} \chi^{2}$ test comparing allele frequencies between Koreans and other populations.

Table 2. Numbers of patients admitted to the intensive care unit (ICU) with 2009 pandemic influenza A (H1N1) in Korean and European countries

\begin{tabular}{lccccc}
\hline Populations & $\begin{array}{l}\text { All H1N1-positive } \\
\text { cases }\end{array}$ & $\begin{array}{l}\text { Nonsevere } \\
\text { cases, } n(\%)\end{array}$ & $\begin{array}{l}\text { Severe cases (ICU } \\
\text { admission), } n(\%)\end{array}$ & $\begin{array}{l}p \\
\text { value }^{\mathrm{a}}\end{array}$ \\
\hline Korea & 709 & $634(89.42)$ & $75(10.58)$ & - & 17 \\
Europe & 3,912 & $3,572(91.31)$ & $340(8.69)$ & 0.106 & 18 \\
$\quad$ The Netherlands & 2,181 & $1,962(89.96)$ & $219(10.04)$ & 0.681 & 0.210 \\
$\quad$ Spain & 585 & $510(87.18)$ & $75(12.82)$ & $<0.001$ & 19 \\
$\quad$ Italy & 1,146 & $1,100(95.99)$ & $46(4.01)$ & \\
\hline
\end{tabular}

${ }^{\mathrm{a}} \chi^{2}$ test comparing nonsevere and severe cases between Koreans and other populations.

$36.3,95 \%$ confidence interval $22.3-59.3, p<0.001)$. However, there were no significant differences in the genotype and allele frequencies of this polymorphism among Northeast Asian populations.

As a significant difference in the genotype and allele frequencies of the IFITM3 SNP was observed between Koreans and Europeans, we compared disease severity in patients with pandemic 2009 IAV infection based on the published literature describing the clinical characteristics of patients with this viral infection. The rate of ICU admissions was not significantly different between the Korean and these 3 European populations $(p=0.106)$. In the Italian population, the rate of ICU admissions was significantly lower than in the Korean population $(p<0.001)$ (Table 2). The rate of deaths among all positive cases with pandemic 2009 IAV infection was significantly lower in Koreans than Europeans $(p<0.001)$ (Table 3$)$.

The IFITM family proteins are antiviral, cell-intrinsic restriction factors for a wide range of highly pathogenic human viruses [5]. Among these proteins, IFITM3 was first identified as a putative IAV restriction factor in 2009 $[6,11]$. Brass et al. [6] noted IFITM3 as a candidate IAV restriction factor because IFITM3 is related to IFN. Eight distinct siRNAs targeting IFITM3 were shown to increase IAV infection, and depletion of IFITM3 significantly reduces the antiviral effect of either IFN- $\gamma$ or $-\alpha$. In addition, these authors detected that overexpression of IFITM3 restricts the early replication of IAV. However, their study was limited to in vitro results.

Everitt et al. [8] performed a functional analysis of the IFITM3 gene using a knockout mouse model. Mice lacking IFITM3 showed acute pneumonia when inoculated with a normally low-pathogenicity murine-adapted H3N2 IAV. In addition, these authors found that hospitalized individuals exhibited a high frequency of the minor IFITM3 allele, rs12252-C. The genotype $(p<0.01)$ and allele frequencies $(p<0.01)$ of this SNP were statistically associated with hospitalization of patients with pan- 
Table 3. Numbers of deaths with 2009 pandemic influenza A (H1N1) in East Asians and Europeans

\begin{tabular}{lclll}
\hline $\begin{array}{l}\text { Popu- } \\
\text { lations }\end{array}$ & $\begin{array}{l}\text { All positive } \\
\text { cases with } \\
\text { influenza A } \\
(\text { H1N1) }\end{array}$ & $\begin{array}{l}\text { Deaths, } \\
n(\%)\end{array}$ & $\begin{array}{l}p \\
\text { value }^{\mathrm{a}}\end{array}$ & Ref. \\
\hline Korea & 750,000 & $252(0.034)$ & - & 20 \\
China & 127,614 & $799(0.626)$ & $<0.001$ & 21 \\
Japan & $20,660,000$ & $198(0.001)$ & $<0.001$ & 22 \\
UK & 29,194 & $436(1.494)$ & $<0.001$ & 23 \\
Spain & 10,162 & $344(3.385)$ & $<0.001$ & 23 \\
\hline
\end{tabular}

${ }^{a} \chi^{2}$ test comparing deaths between Koreans and other populations.

demic 2009 IAV infection. Furthermore, functional assays indicated that the CC genotype of the IFITM3 gene has increased influenza virus infection in vitro [8]. Their findings triggered further research of IFITM3 rs12252, which is associated with H1N1 IAV in many different human ethnic groups.

The distribution of the rs12252-C allele in Han Chinese is much more widespread than in Caucasians. It has been reported that the distribution of the CC genotype is 69 and 25\% in Chinese patients with severe pandemic IAV infection and mild infection, respectively. Furthermore, this genotype was found to be associated with a sixfold increased risk of severe infection compared with the CT and TT genotypes [9]. However, Mills et al. [10] performed genotyping of rs12252 in patients with H1N1 influenza infection and severe pneumonia, and concluded that a correlation existed between rs12252 CC homozygotes and susceptibility to mild influenza, but they could not ascertain the correlation between CC homozygotes and severe influenza reported in previous studies.

However, a meta-analysis including 3 of the abovementioned studies and 1 study of H7N9 showed that, compared with the $\mathrm{T}$ allele, the $\mathrm{C}$ allele of the IFITM3 rs 12252 polymorphism was related to an approximately $70 \%$ increased risk of influenza. In addition, Caucasians with the CC homozygous genotype of this SNP exhibited higher vulnerability to influenza than those with the CT and TT genotypes. Although the TC or CC genotypes of the IFITM3 rs12252 polymorphism in Northern Europeans do not significantly differ from those observed in Europeans, the numbers of ICU-admitted patients were different between the Netherlands and Italy (Table 2). This difference may be due to the ethnic background or medical conditions of patients. Furthermore, Asians showed a significant correlation between the rs12252 SNP of the IFITM3 gene and vulnerability to influenza, as detected in alleles, and dominant and recessive models. However, for individuals with mild infection, no significant association was observed. These findings suggested that the rs $12252 \mathrm{~T}>\mathrm{C}$ SNP is significantly correlated with an increased risk of severe influenza but not with the likelihood of early influenza infection [12]. The discrepancy between the results of Mills et al. [10] and meta-analysis data may be due to differences in sample sizes, statistical power, and ethnic groups.

We report that the genotype and allele frequencies of the IFITM3 rs12252 polymorphism in a healthy Korean population do not significantly differ from those previously observed for the Japanese $(p=0.051)$ and the Chinese population $(p=0.145)$. However, the genotype frequencies are significantly different from those reported in Europeans $(p<0.001)$, the CEU (Utah Residents with Northern and Western European ancestry)/FIN (Finnish in Finland)/GBR (British in England and Scotland)/IBI (Iberian population in Spain)/TSI (Toscani in Italia), UK $(p<0.001)$, northern European $(p<0.001)$, and YRI (Yoruba in Ibadan, Nigera) $(p<0.001)$ populations (Table 1$)$. In addition, the genotype frequency for rs12252 SNP in our data is significantly different from that in the study by Seo et al. [13]. This result may be due to differences in the genotyping method used. In the paper by Seo et al. [13], genotyping of this SNP was performed by restriction fragment length polymorphism (RFLP) analysis. However, we carried out direct DNA sequencing analysis. In the previous study, direct DNA sequencing was more accurate and feasible in detecting SNPs than RFLP [14]. In addition, we performed HWE tests for the data of 2 groups. The $p$ value score $(p=0.536)$ of our data was higher than that of their group $(p=0.142)$. These results suggest that the genotyping results of our group are more reliable than those of Seo et al. [13]. We searched the literature in PubMed for data on hospitalized influenza A patients (nonsevere and severe cases, including cases of death) and performed a statistical analysis. Our data show that death rates of patients with IAV infection are significantly different in the Korean population $(0.034 \%)$ compared with those of the Japanese $(0.001 \%)$ and the Chinese $(0.626 \%)$ population. Unexpectedly, the prevalence of deaths following 2009 pandemic IAV infection was much lower in Korean, Japanese, and Chinese populations than in Europeans (British and Spanish; $p<0.001$ ) (Table 3 ). This result suggests the possibility that a genotype of the IFITM3 rs12252 polymorphism is not a functional SNP regarding the disease severity of IAV infec- 
tion. Another possibility is presumably the underlying medical conditions of patients with $\mathrm{H} 1 \mathrm{~N} 1$ influenza infection. It is possible that the rate of death was influenced by other risk factors including vaccination, antiviral administration, time to hospital admission, and high-risk medical conditions such as diabetes mellitus, preexisting heart disease, immunosuppression, and lung disease [15, 16]. In addition, the mean age of 709 Korean cases positive for IAV infection was 50.69 years. Of them, 280 (39.5\%) patients were male and $429(60.5 \%)$ were female. The differences in the mean age and gender distribution were found between healthy Koreans and confirmed positive cases. We cannot exclude a selection bias between both groups. Finally, since the percentage of deaths in East Asians is inversely proportional to cases positive for IAV (H1N1) infection, the difference in confirmed cases may influence the rate of deaths. In the current study, there are some limitations regarding the information on patient conditions. Thus, in the future, we will investigate the correlation between disease severity and IFITM3 rs12252 polymorphism in Korean patients with severe and mild IAV infections to confirm previous studies. Because the functional study of the IFITM3 rs12252 SNP has not been performed using a transgenic mouse model, there might be a discrepancy between preclinical experiments and our results. In conclusion, the rs12252 polymorphism of the IFITM3 gene did not significantly correlate with the disease severity of IAV infection.

\section{Acknowledgments}

This research was supported by the Basic Science Program through the National Research Foundation of Korea (NRF), the Ministry of Education, Science, and Technology (2015R1D1A1A010599), the Korea Institute of Planning and Evaluation for Technology in Food, Agriculture, Forestry, and Fisheries (IPET) through the Agriculture, Food, and Rural Affairs Research Center Support program, and the Ministry of Agriculture, Food, and Rural Affairs (716002-7). Bioresources were provided by the National Biobank of Korea, the Centers for Disease Control and Prevention, Republic of Korea (4805-301, 4851-302 and -307). Mr. Yong-Chan Kim was supported by the BK21 Plus program in the Department of Bioactive Material Sciences.

\section{Disclosure Statement}

The authors have no conflict of interest.

\section{References}

1 Dawood FS, Iuliano AD, Reed C, Meltzer MI, Shay DK, Cheng PY, Bandaranayake D, Breiman RF, Brooks WA, Buchy P, Feikin DR, Fowler KB, Gordon A, Hien NT, Horby P, Huang QS, Katz MA, Krishnan A, Lal R, Montgomery JM, Molbak K, Pebody R, Presanis AM, Razuri H, Steens A, Tinoco YO, Wallinga J, Yu H, Vong S, Bresee J, Widdowson MA: Estimated global mortality associated with the first 12 months of 2009 pandemic influenza A H1N1 virus circulation: a modelling study. Lancet Infect Dis 2012;12:687695.

2 Zhong Y, Zhou J, Liang N, Liu B, Lu R, He Y, Liang $\mathrm{C}, \mathrm{Wu}$ J, Zhou Y, Hu M, Zhou J: Effect of Maxing Shigan Tang on H1N1 influenza A virus-associated acute lung injury in mice. Intervirology 2016;59:267-274.

3 Friedman RL, Manly SP, McMahon M, Kerr IM, Stark GR: Transcriptional and posttranscriptional regulation of interferon-induced gene expression in human cells. Cell 1984;38: 745-755.

4 Li K, Markosyan RM, Zheng YM, Golfetto O, Bungart B, Li M, Ding S, He Y, Liang C, Lee JC, Gratton E, Cohen FS, Liu SL: IFITM proteins restrict viral membrane hemifusion. PLoS Pathog 2013;9:e1003124.
5 Huang IC, Bailey CC, Weyer JL, Radoshitzky SR, Becker MM, Chiang JJ, Brass AL, Ahmed AA, Chi X, Dong L, Longobardi LE, Boltz D, Kuhn JH, Elledge SJ, Bavari S, Denison MR, Choe H, Farzan M: Distinct patterns of IFITM-mediated restriction of filoviruses, SARS coronavirus, and influenza A virus. PLoS Pathog 2011;7:e1001258.

6 Brass AL, Huang IC, Benita Y, John SP, Krishnan MN, Feeley EM, Ryan BJ, Weyer JL, van der Weyden L, Fikrig E, Adams DJ, Xavier RJ, Farzan M, Elledge SJ: The IFITM proteins mediate cellular resistance to influenza A H1N1 virus, West Nile virus, and dengue virus. Cell 2009;139:1243-1254.

7 Feeley EM, Sims JS, John SP, Chin CR, Pertel T, Chen LM, Gaiha GD, Ryan BJ, Donis RO, Elledge SJ, Brass AL: IFITM3 inhibits influenza A virus infection by preventing cytosolic entry. PLoS Pathog 2011;7:e1002337.

8 Everitt AR, Clare S, Pertel T, John SP, Wash RS, Smith SE, Chin CR, Feeley EM, Sims JS, Adams DJ, Wise HM, Kane L, Goulding D, Digard P, Anttila V, Baillie JK, Walsh TS, Hume DA, Palotie A, Xue Y, Colonna V, Tyler-Smith C, Dunning J, Gordon SB, Gen II, Investigators $\mathrm{M}$, Smyth RL, Openshaw $\mathrm{PJ}$, Dougan G, Brass AL, Kellam P: IFITM3 restricts the morbidity and mortality associated with influenza. Nature 2012;484:519-523.
9 Zhang YH, Zhao Y, Li N, Peng YC, Giannoulatou E, Jin RH, Yan HP, Wu H, Liu JH, Liu N, Wang DY, Shu YL, Ho LP, Kellam P, McMichael A, Dong T: Interferon-induced transmembrane protein-3 genetic variant rs 12252-C is associated with severe influenza in Chinese individuals. Nat Commun 2013;4: 1418.

10 Mills TC, Rautanen A, Elliott KS, Parks T, Naranbhai V, Ieven MM, Butler CC, Little P, Verheij T, Garrard CS, Hinds C, Goossens H, Chapman S, Hill AV: IFITM3 and susceptibility to respiratory viral infections in the community. J Infect Dis 2014;209:1028-1031.

11 Shapira SD, Gat-Viks I, Shum BO, Dricot A, de Grace MM, Wu L, Gupta PB, Hao T, Silver SJ, Root DE, Hill DE, Regev A, Hacohen N: A physical and regulatory map of host-influenza interactions reveals pathways in $\mathrm{H} 1 \mathrm{~N} 1$ infection. Cell 2009;139:1255-1267.

12 Xuan Y, Wang LN, Li W, Zi HR, Guo Y, Yan WJ, Chen XB, Wei PM: IFITM3 rs12252 T>C polymorphism is associated with the risk of severe influenza: a meta-analysis. Epidemiol Infect 2015;143:2975-2984.

13 Seo GS, Lee JK, Yu JI, Yun KJ, Chae SC, Choi SC: Identification of the polymorphisms in IFITM3 gene and their association in a Korean population with ulcerative colitis. Exp Mol Med 2010;42:99-104. 
14 Davis AH, Jianhua Wang, Tsang TC, Harris DT: Direct sequencing is more accurate and feasible in detecting single nucleotide polymorphisms than RFLP: using human vascular endothelial growth factor gene as a model. Biol Res Nurs 2007;9:170-178.

15 Campbell A, Rodin R, Kropp R, Mao Y, Hong Z, Vachon J, Spika J, Pelletier L: Risk of severe outcomes among patients admitted to hospital with pandemic (H1N1) influenza. CMAJ 2010;182:349-355.

16 Viasus D, Pano-Pardo JR, Pachon J, Campins A, Lopez-Medrano F, Villoslada A, Farinas MC, Moreno A, Rodriguez-Bano J, Oteo JA, Martinez-Montauti J, Torre-Cisneros J, Segura F, Gudiol F, Carratala J; Novel Influenza A (H1N1) Study Group of the Spanish Network for Research in Infectious Diseases (REIPI): Factors associated with severe disease in hospitalized adults with pandemic (H1N1) 2009 in Spain. Clin Microbiol Infect 2011;17:738-746.
17 Oh WS, Lee SJ, Lee CS, Hur JA, Hur AC, Park YS, Heo ST, Bae IG, Park SW, Kim ES, Kim HB, Song KH, Lee KS, Lee SR, Yeom JS, Lee SJ, Kim BN, Kwak YG, Lee JH, Kim YK, Kim HY, Kim NJ, Oh MD: A prediction rule to identify severe cases among adult patients hospitalized with pandemic influenza A (H1N1) 2009. J Korean Med Sci 2011;26:499506.

18 van 't Klooster TM, Wielders CC, Donker T, Isken L, Meijer A, van den Wijngaard CC, van der Sande MA, van der Hoek W: Surveillance of hospitalisations for 2009 pandemic influenza $\mathrm{A}(\mathrm{H} 1 \mathrm{~N} 1)$ in the Netherlands, 5 June - 31 December 2009. Euro Surveill 2010;15:19461.

19 Tramuto F, Maida CM, Bonura F, Perna AM, Puzelli S, De Marco MA, Donatelli I, Aprea L, Firenze A, Arcadipane A, Palazzo U, Vitale F: Surveillance of hospitalised patients with influenza-like illness during pandemic influenza A (H1N1) season in Sicily, April 2009-December 2010. Euro Surveill 2011;16:19957.
20 Kim JY: The 2009 H1N1 pandemic influenza in Korea. Tuberc Respir Dis 2016;79:70-73.

21 Liang W, Feng L, Xu C, Xiang N, Zhang Y, Shu Y, Wang H, Luo H, Yu H, Liang X, Li D, Lee CK, Feng Z, Hou Y, Wang Y, Chen Z, Yang W: Response to the first wave of pandemic (H1N1) 2009: experiences and lessons learnt from China. Public Health 2012;126: 427-436.

22 Sugaya N, Shinjoh M, Mitamura K, Takahashi $\mathrm{T}$ : Very low pandemic influenza A (H1N1) 2009 mortality associated with early neuraminidase inhibitor treatment in Japan: analysis of 1,000 hospitalized children. J Infect 2011;63:288-294.

23 Reintjes R, Das E, Klemm C, Richardus JH, Kessler V, Ahmad A: "Pandemic public health paradox": time series analysis of the 2009/10 influenza $\mathrm{A} / \mathrm{H} 1 \mathrm{~N} 1$ epidemiology, media attention, risk perception and public reactions in 5 European countries. PLoS One 2016;11: e0151258. 